UNIVERSITA' DEGLI STUDI DI TRENTO - DIPARTIMENTO DI ECONOMIA

\title{
HOW IS FUTURES TRADING AFFECTED BY THE MOVE TO A COMPUTERIZED TRADING SYSTEM? LESSONS FROM THE LIFFE FTSE 100 CONTRACT
}

Christopher L. Gilbert

and

Herbert A. Rijken 
The Discussion Paper series provides a means for circulating preliminary research results by staff of or visitors to the Department. Its purpose is to stimulate discussion prior to the publication of papers.

Requests for copies of Discussion Papers and address changes should be sent to:

Dott. Stefano Comino

Dipartimento di Economia

Università degli Studi

Via Inama 5

38100 TRENTO ITALY 


\title{
How is Futures Trading Affected by the Move to a Computerized Trading System? Lessons from the LIFFE FTSE 100 Contract
}

\author{
Christopher L. Gilbert ${ }^{*}$ \\ Herbert A. Rijken ${ }^{\text {** }}$ \\ Initial version: 28 March, 2001 \\ This revision: 15 March 2005
}

\begin{abstract}
We consider the impact of the May 1999 move to screen trading of the LIFFE FTSE 100 index futures contract. This resulted in a narrowing of the effective spread. Spread determinants are broadly similar in the two regimes. The narrowing of the spread appears due to increased competition among traders and a decline in tick-level volatility rather than to the way these or other variables affect the spread. Market depth appears largely unaffected. Under screen trading, realized spreads widen as more limit orders are taken up rather than in relation to order size.
\end{abstract}

JEL Categories: G13, G14

* Dipartimento di Economia, Universitá degli Studi di Trento, Via Inama 5, 38100 Trento, Italy. Email: cgilbert@economia.unitn.it

** FEWEB, Vrije Universiteit, De Boelelaan 1105, 1081 HV Amsterdam, The Netherlands. Email: hrijken@,feweb.vu.nl

We are grateful to Euronext-LIFFE for data and comments on an early draft of this paper, and also to Paul Dawson, Bert Menkveld, seminar participants at the Vrije Universiteit, the University of Pennsylvania, at the Asia-Pacific Finance Association, Bangkok, July 2001 and at the European Financial Management Association, London, July 2002, and an anonymous referee for comments. All errors remain our responsibility. 


\section{Introduction}

The shift to computerized trading systems (CTS's) is one of the most important current developments in the trading of both equities and derivatives. This shift has in part been driven by the belief that CTS trading offers lower transaction costs than traditional floor-based trading systems. In efficient trading systems, the main element of trading costs is the bid-ask spread which are the focus of this contribution. Other factors which may have influenced the shift to CTS's include the hope of major exchange-users that integrated trading systems may reduce the costs of operating across different exchanges, the wish for increased transparency and greater information availability for traders working from their own offices.

Although most of the existing discussion in the academic literature relates to equities trading, the issues are largely common to futures markets as well. A number of considerations - most notably high trading volume, data quality, exchange ownership of the traded instruments, and the absence of any "upstairs" market - makes it easier to obtain clear comparisons across the two types of trading system by looking at futures markets. Our concern in this paper is with futures trading.

Until recently, there was wide industry acceptance that open outcry futures markets should be more liquid, and therefore less expensive to trade, than comparable CTS markets. This was also the view expressed by Grossman and Miller (1986), Miller (1991) and Massimb and Phelps (1994). It relies primarily on the claim that CTS markets provide a much higher degree of anonymity than does open outcry trading. In particular, floor traders are able to obtain information from the order flow in the pit (who is trading with whom and in what size) in order to infer likely future trading patterns. Miller argues that, as a consequence, CTS market makers are more vulnerable to adverse selection requiring them to seek higher spreads - see, for example, Glosten and Milgrom (1985). Massimb and Phelps (1994) state that although operating costs are lower with screen-based trading, open outcry has the advantage of higher liquidity. They suggested hybrid trading systems could evolve which combine the cost advantages of the former with them liquidity advantages of the latter.

Pirrong (1996), who compared screen-based and open outcry futures trading, suggested that the comparison is more balanced.

Costly "out-trade" errors are likely to be lower in screen trading.

Screen trading facilitates credit monitoring by the exchange. 
CTS trading provides fewer possibilities for traditional trading malpractices, which can discourage liquidity.

Pirrong argued that there is no a priori reason to suppose that one or other system will consistently generate the higher level of liquidity. Fremault Vila and Sandmann (1996) also took the view that further evidence is required before definitive conclusions can be reached.

In the equities context, particularly in the United States, the major exchanges face competition from alternative trading systems (ATS's) - see Miller (1990). Domowitz and Steil (1999) have argued that one of the principal avenues by which changes in trading technology affect trading costs is by increasing market contestability. In particular, users can opt to place orders either through the exchange or an ATS depending on the relative liquidity of the two markets at the particular instant of time - see Domowitz (2001). Unlike equities exchanges, derivatives exchanges own the contracts that they trade. The consequence is that competition is confined to competition between exchanges on similar contracts, and competition between exchanges and over the counter (OTC) markets where the OTC market offers trades "look alike" contracts. The fact that exchange contracts on one exchange cannot be used to offset either OTC contracts or contracts on a second exchange limits the contestability of derivatives trading. Despite these differences, we suggest that a similar effect is at work in derivatives trading to that propounded by Domowitz and Steil (1999) in equities trading, namely the adoption of CTS trading increases competition by reducing the costs of accessing the exchange.

Evidence in support of the traditional view is provided by Coppejans and Domowitz (1999) who reported that adverse selection costs in currency futures trading were $23 \%-32 \%$ higher on the off-hours GLOBEX trading by comparison with trading of the same contracts during normal trading hours on the Chicago Mercantile Exchange floor. However, they also reported slightly lower adverse selection costs for the S\&P 500 contract on GLOBEX compared with CME floor. Earlier, Pirrong (1996) examined trading in the LIFFE and DTB bund futures contracts over the twelve month period July 1992 to June 1993, a period in which LIFFE still dominated the bund market. He found that in many months, DTB spreads were significantly lower than LIFFE spreads, while there was no month in which the LIFFE spread was lower than the DTB spread.1 Grünbichler et al (1994) studied differences between

\footnotetext{
${ }^{1}$ Pirrong's regression estimates also indicated that market depth was greater on the DTB over this period. He therefore concluded that the DTB was both less expensive and more liquid
} 
OTC trading and floor trading by comparing the rapidity of information assimilation on the German equities market, which utilized a trading floor, and in the screen-traded DAX equity index futures contract. Naidu and Rozeff (1994) and Blennerhasset and Bowman (1998) looked at trading costs before and after the introduction of screen trading. This is the more relevant experience for US exchanges currently contemplating the possibility of abandoning open outcry trading.

Three previous studies have considered the move of the LIFFE FTSE 100 contract to screen trading. Hill and Frino (2001) compare spreads on index futures contracts traded on the Hong Kong (HKFE), London (LIFFE) and Singapore (SFE) markets prior to and post automation. They find that spreads narrowed on the HKFE and SFE but widened on LIFFE. Gwilym and Alibo (2003) demonstrate that the FTSE's move to screen trading was accompanied by a reduction in the extent of price clustering, specifically the extent to which price quotes and trades cluster at $£ 10$ tick values even though the minimum tick size was $£ 5$. They note that this reduction in clustering is equivalent to a reduction in effective tick size. Finally, Copeland et al. (2004) argue that market inefficiencies remained in both the Euronext-LIFFE FTSE 100 and the French CAC 40 contracts after the shift to screen trading. Their results suggest that these inefficiencies may be associated with anomalous trading in the period immediately following the morning opening of the markets.

Adoption of a CTS has effects other than those which directly impact spreads. Most obviously, open outcry futures trading has no memory - a quote is only good "so long as the trader's breath is warm". By contrast, screen futures trading operates via a limit order book. An open limit order book will also substantially increase market transparency and this transparency should result in superior price discovery - see Degryse and Van Achter (2001). This may be expected to result in lower price volatility at high frequencies. At the same time, but depending on the specification of the trade matching algorithm, the operation of the limit order book may generate a significant amount of order splitting which may complicate inference.

In this paper, we look at the specific comparison of open outcry and CTS futures trading by considering the impact of the move of trading in the LIFFE UK index future (the

than the LIFFE bund contract. Shyy and Lee (1995) reported lower spreads on LIFFE. Kofman and Moser (1996) found that the spreads were equal on the two markets. See also Franses et al (1997) and Frino et al (1998). 
FTSE 100 future) from open outcry to CTS trading in May 1999.2 The size of the LIFFE market makes this comparison more relevant to similar moves under consideration by US futures exchanges than changes introduced by less liquid exchanges. The paper makes four distinct contributions to the literature:

We compare the bid-ask spread before and after the introduction of computerized trading. Here we confirm the finding that LIFFE's move to screen trading of index futures contracts is associated with a narrowing of spreads, contrary to the claim in Hill and Frino (2001).

We consider the adjustment experience in the weeks immediately following automation.

We compare the determinants of the spread under open outcry and screen trading and use these estimates to explore the origin of the changes in spread arising from the move to a CTS. We analyze depth in the open outcry and screen market.

The structure of this paper is as follows. In section II, we look at the LIFFE FTSE 100 futures contract, and in section III we give details of the trading systems employed by LIFFE before and after May 1999. In section IV, we review methods for measuring the bid-ask spread, and for identifying trade direction (whether initiated by a buy or sell order) from trade records. This allows us to examine, in section $\mathrm{V}$, whether the spread has widened or narrowed as a consequence of the move to screen trading. In section VI, we consider the broader question of the determinants of the spread in the two regimes, and in section VII we look at adverse selection and market depth. Section VIII contains conclusions.

\section{The LIFFE FTSE 100 Futures Contract}

Over the period we consider, LIFFE traded FTSE 100 contracts trade for March, June, September and December cash settlement against the FTSE 100 index. Three contracts were traded at any point in time over the period covered by our data, although this has more recently been increased to four. The contract is closely arbitraged with the shares which comprise the FTSE 100 index on the LSE - see Taylor et al (2000). The current contract size is $£ 10$ per index point (reduced from $£ 25$ from the start of trading of the June 1998 contract) and the tick size is one half index point (£5).

Trading in FTSE futures has passed through three phases:

\footnotetext{
${ }^{2}$ LIFFE is the London International Financial Futures Exchange. The FTSE 100 is the Financial Times Stock Exchange index of the 100 leading shares traded on the London Stock Exchange (the LSE). In 2001, LIFFE became part of Euronext.
} 
i) An initial period, from 1984 to 1986, when volume and open interest were at low levels.

ii) A seven year period of steady growth from 1987 to 1993.

iii) The mature period since 1994 over which no trend is apparent in either volume or open interest.

Volume and open interest both increased slightly in the period of screen trading, but the growth was consistent with those seen earlier under the open outcry system. The data are consistent with the view that the change in trading system did not affect trading volumes or open interest.

Except in the three weeks prior to contract expiration, activity concentrated in the front contract, with relatively little spread trading. Volume in the front contract remained high, and generally higher than the second contract, until the final day of trading. We therefore confine attention to the front contract, and switch to the next contract at the start of the final day of trading of the old contract. This involves little information loss. The fact that trading in the FTSE 100 is on an "outright" rather than a spread basis is important both because in spread trading we would need to identify the costs associated with a pair of transactions, and because screen trading of spread contracts is more complicated than of outright contracts (Pirrong, 1996). ${ }^{3}$

We analyze the complete tick data record relating to the FTSE 100 contract over the period 1 April 1998 to 13 October 2000. The choice of start data was motivated by the change in contract size from $£ 25$ per index point to $£ 10$ per index point which became effective for the front contract from 23 March 1998 (the day after the expiration of the March 1998 contract, the last of the $£ 25$ contracts). The change in contract size complicates the comparison of volumes before and after the switch. ${ }^{4}$ The switch to screen trading took place over the weekend of 8-9 May 1999. We terminate the sample on 13 October 2000 just prior to the start of trading on the Mini FTSE 100 contract on 17 October. The Mini contract is completely fungible with the main FTSE 100 contract at the rate of five Mini contracts for one FTSE 100 contract. $^{5}$ This change complicates interpretation of the tick data, and so we chose to remain with data which is clearly comparable before and after the switch to screen

\footnotetext{
3 We dropped the small number of trades identified as spread trades from our analysis.

${ }^{4}$ A pre-March 1998 peak in the trading volume distribution at 3 contracts was replaced by a post-March peak at 10 contracts. This switch is not completely captured by a conversion factor of 2.5.

${ }^{5}$ See LIFFE General Notice \#1680, issued 25 September 2000.
} 
trading. Our sample therefore consists of 13 months of open outcry trading and 17 months of screen trading.

We divide the sample into three sub-samples - one open outcry subsample and two CTS subsamples.

Period I: 1 April 1998 to 7 May 1999 (the final day of open outcry)

Period II: 10 May 1999 to 18 June 1999

Period III: 21 June 1999 to 13 October 2000.

Period II was a learning period in which traders were becoming familiar both with the screen trading system and with the trading behaviour that it generates. We show that spreads were both wider and more volatile in this six week period than in the weeks before and the weeks that followed.

\section{The LIFFE Open Outcry and Computerized Trading Systems}

The characteristics of any CTS are determined by its rules and operating algorithms. Since May 1999, LIFFE has traded its financial futures products under the LIFFE CONNECT ${ }^{\mathrm{TM}}$ system. Details of this system are provided in an appendix. Although the system allows a variety of order types, the principal orders are limit orders, which remain on the system until either executed or withdrawn (or until the market close), and market orders, which execute against limit orders. There are no designated market makers in FTSE trading. We interpret the market making function as the placing of limit orders, irrespective of who places these orders. Trading operates under a simple lexicographic algorithm of price priority followed by time priority.

The open outcry system which prevailed until May 1999 is not characterizable in terms of an algorithm. Orders were either offers to buy (bids) or to sell (offers), which were either met or failed to be met by market orders. At any point in time, the best buy and sell offers had priority. Market makers had an element of discretion as to which market orders they filled, although by convention locals were always permitted to participate in large orders. Bids and offers which were not filled, or only incompletely filled, were either repeated or died. Open outcry therefore lacks the algorithmic memory provided by the limit order facility of CTS's.

The LIFFE tick dataset records transactions prices and volumes together with best bid and ask quotes and associated volumes. Under CTS trading, a quote is only recorded if it is 
the best quote on its respective side of the market. If, for example, the best ask price is hit, it will automatically be replaced by the next best ask in the limit order book which will appear as a new quote. If the best ask price is only partially filled, it will be replaced by a new quote at the same price for the residual quantity. The most recent recorded quotes are therefore best quotes. Traders have access to much greater information on the limit order book - the precise information depending on their software implementation.

Table 1 gives statistics for the average number of trades, trading volume per day and volume per trade in each of the three periods we have identified. Trading time is recorded only to the second. In what follows, we have aggregated Periods II and III trades with the same time-stamp, provided they are on the same side of the market, and imputed a weighted average price. This will inevitably involve a degree of misclassification of separate trades which happen to coincide. We return to this issue in section VI.

Referring to rows 2 and 3 of the table, one sees that although daily volume has shown a modest increase over time, volume per trade has reduced to one third of its open outcry level. This change, which took place sharply on the day that the shift to screen-based trading took place, is discussed by Gwilym and Alibo (2003). The splitting of large orders appears to be a consequence of the operation of the limit order book together with the lexicographic priority rule.

Prior to the May 1999 move to screen trading, the FTSE 100 contract was also traded during an evening screen session using the APT trading system. Like CONNECT, the APT system supported a limit order book. In May 1999, evening trading also moved onto the CONNECT system. Although evening volumes have always been small, they provide a partial control for the results relating to normal trading hours. No change is apparent in average trade size in evening trading, where the limit order book facility was always available, comparable to that during trading in normal hours - indeed volume per trade increased modestly with the move from the APT system to CONNECT.

\section{Measurement of the Bid-Ask Spread and Identification of Trade Direction}

Spreads may either be measured directly from quote data, or indirectly from transactions data. Different authors employ different spread measures and nomenclatures are not always consistent. Broadly, we may distinguish three classes of spread definition: 
1. The nominal spread: This defines the spread as the difference between the best ask and bid quotes at any point of time. The definition implies that spreads are common across market participants.

2. The effective spread: Traders may be able to trade at superior prices to those quoted. In other circumstances, for example for trades with large size, transactions prices may be less good than quoted prices. Effective spreads will differ from nominal spreads in part because narrow spreads will induce greater trading volumes and in part because different transactors have different trading opportunities. The effective spread definition use transactions prices in conjunction with price quotations to obtain a measure of actual spreads faced by market participants.

3. The realized spread is conceptually a variant of the effective spread, but is defined in terms of trade profitability, as measured by the difference between the selling and the buying price. There will be two components to profitability - the costs of trading plus the capital gain or loss on the position as the consequence of the arrival of new information over the holding period. If the holding period is made as short as possible, by comparing the transactions price with the next trade on the opposite side of the market, only the first, trading cost, component will be present.

One way of comparing these definitions is to look at their informational requirements. Price quotes distinguish between bids and asks, but we do not normally know the direction of a trade for which a transactions price is recorded, i.e. whether it is a trade against a bid, an ask price or some other price. Nominal spreads use only price quotations, while effective spreads use only transactions prices together with the direction determination.

Effective and realized spread measures therefore require identification of trade direction. Direction is therefore typically inferred by comparing transactions prices with quotes on either side of the market. A number of well-known algorithms have been designed for this purpose, mainly in relation to equities datasets:

- Hasbrouck (1988) classified trades as (public) buys if they were above the quote midprice (the average of the bid and ask prices) and sells if they were below the mid-price. Trades at the mid-price are not classified. The effective spread is twice the absolute value of the difference between the trade price and the quote mid-price.

- The standard tick test, formalized by Lee and Ready (1991, p.735), classifies a trade as a buy if it occurs on an uptick or zero-uptick, and a sell if it occurs on a downtick or zero- 
downtick. ${ }^{6}$ In principle, the tick test can classify all trades. This allows construction of a realized spread, measured as the difference between sequential buy and sell prices.

- Lee and Ready (1991) note that, on equities data, most classification problems arise when transaction prices are within the nominal spread. They therefore suggest the hybrid classification (LR) method which uses Hasbrouck's (1988) criterion, augmented by the tick rule for trades which take place at the mid-price.

- Ellis et al (2000) modify the LR algorithm by using the tick test to classify all trades which take place within the nominal spread.

A particular problem in the analysis of equities data is that many transactions take place within the spread. This is not a significant problem in the dataset we examine, and we believe it is unlikely to be a serious problem in many futures tick datasets.

\section{The FTSE 100 Bid-Ask Spread}

Our FTSE 100 dataset has the same structure under both open outcry and screen trading but interpretation differs under the two regimes. In each case we have a time-ordered sequence of bid quotations, ask quotations and transactions. Direction is recorded for quotes but not trades, and volumes for trades but not quotes. The identification of trade direction requires the matching of each transaction with the appropriate quote. The dataset records only the best quotes at any point of time and does not provide any information on the limit order book. ${ }^{7}$

Under open outcry, a new best quote automatically over-rode the previous best quote on that side of the market. If that quote became exhausted by a trade, a new transaction on that side of the market was obliged to await a fresh quote. However, in active trading it was possible for the sequence of trades and quotes to overlap, so if a trade and quote were made at nearly the same time in different areas of the pit, the trade might match with an earlier quote. Furthermore, inaccuracies in time-stamping could distort the precise sequence of events.

\footnotetext{
${ }^{6}$ A trade is an uptick (downtick) if it takes place at a higher (lower) price than the previous trade. It is a zero-uptick (zero-downtick) if it takes place at the same price as the previous trade and the previous price change was classified as an uptick or zero-uptick (downtick or zero-downtick). A reverse tick criterion is obtained by replacing "previous" with "subsequent" in this definition.

${ }^{7}$ We are able to infer part of the limit order book when a trader takes out multiple quotes in a single trade.
} 
Time-stamping problems disappear under screen trading so we may be confident that the recorded sequence of quotes and trades is the actual sequence. Furthermore, all traders react to the same screen information, so pit fragmentation problems disappear. The data generated in screen trading are therefore cleaner than those generated from open outcry - see Gwilym and Thomas (1998) who make the same point. However, the limit order book implies that trades automatically generate apparently fresh quotes by uncovering orders in the limit order book. This appears in the dataset as quotes appearing with the same time-stamp as the immediately preceding trades.

Nominal spreads can be measured from best bid and ask quotes whenever we have quotes on both sides of the market. In order to measure what the market actually faces, we have to measure the effective spread. A definition of the effective spread proposed by Neal (1992) is the current nominal spread, which is the difference between the two best quotes immediately preceding the trade where this information is available. At times when trading is very active and in a single direction, there may not be fresh quotes on the other side of the market. Inference from earlier quotes is obviously dangerous. The result is that we are unable to calculate the current nominal spread contemporaneous with every trade. We therefore restrict measurement of the current nominal spread to those trades in which we have at least one ask quote and one bid quote are available between the current and the previous trade.

With this restriction, we are able to measure the current nominal spread for $46.6 \%$ of trades under open outcry and to $43.2 \%$ of trades under screen trading. Only $0.1 \%$ of trades in this category are estimated as taking place outside the spread and $4.4 \%$ within the spread under open outcry, while less than $0.1 \%$ of screen trades are recorded as outside the spread and $0.1 \%$ within the spread. The effective absence of trades within and outside the spread has the effect that effective spreads are the same as nominal spreads in our dataset, once nominal spreads have been corrected for trading time.

Turning to the remaining trades, a fresh quote (ask or bid) is available only on one side of the market between the current and the previous trade (true of $31.0 \%$ under open outcry, and $54.8 \%$ of trades under screen trading), or there is no fresh quote between the trade and previous trade on either side of the market (this applies to $22.4 \%$ of trades in our dataset under open outcry but to only $2.0 \%$ of trades under screen trading). These two categories correspond to more active trading conditions - average inter-trade durations of 10.7 seconds under open outcry and 2.6 seconds under screen trading for the trades for which we have a 
single fresh quote and 5.4 seconds and 1.1 second for those for which we have no fresh quote. Two possibilities are open to us. The first is to estimate the incomplete quote data with missing quotes and trade direction inferred from the data available. We have constructed a hybrid algorithm to estimate spreads on this basis reflecting the specific features of our dataset. The second is to rely solely on those transactions for which we have reliable spread information, and to correct for possible sample selection bias in estimation.

In the former case, our hybrid algorithm operates as follows. If an ask quote has been recorded between the current and the previous trade, the current trade is matched with this quote provided it is at a price equal to or greater than the quote; and if a bid quote has been recorded, the trade is matched with that quote provided the trade price is equal to or less than the quote. This still leaves a large proportion of trades as unclassified. We classify these as sales if they take place below the most recent recorded ask quote but at the previous bid quote, but as buys if they take place above bid quote but at the previous ask quote.

When no quotes are available between trades we only classify a trade if the previous trade has been classified. Current trades are classified as sales/buys if previous trades are classified as sales/buys or the current trade price is smaller/greater than the previous trade price. In total, we have classified $82.16 \%$ trades for the open outcry regime and $99.86 \%$ for the automated screen trading regime on this basis. Table 2 provides summary statistics for five spread measures over the three periods we have identified. The numbers in parentheses are standard deviations. We also provide, at the foot of each cell, the number of observation on which these statistics are based. ${ }^{8}$

We consider five spread measures.

Row 1: The average nominal spread. Here we sample in the most recent nominal spread at five minute intervals through each day, where the spread is measured as the distance between the best ask and bid quotes when both are quoted. This spread measure shows a slight fall from 2.21 index points in Period I to 1.81 index points in Period III. Spread variability, measured by the sample standard deviation, is little changed but was higher in Period II.

Row 2: The current nominal spread. This is the difference between the two best quotes immediately preceding the trade, where this information is available - see Neal (1992). This

\footnotetext{
${ }^{8}$ Recall that the standard deviation of a sample mean is the sample standard deviation divided by the square root of the number of observations. Given the large numbers of observations
} 
spread measure shows a fall, from 1.76 index points in Period I to 1.47 index points in Period III. Here, there is some evidence in spread variability. The small proportion of trades which take place outside the spread and the non-classification of trades within the spread makes this measure effectively equivalent to an effective spread. The difference between this and the average nominal spread measures the cost advantage from trade timing (see Theissen, 2002), estimated as 0.45 index points under open outcry and 0.35 index points under screen trading.

Row 3: The weighted current nominal spread. The current nominal spread measure, reported in row 2 , is based on incomplete and possibly non-random samples, and this may result in biased spread estimates. We have noted that trades for which we have full quote information are associated with relatively long inter-trade durations. Because spreads are correlated with trade durations, these estimates are potentially biased. We correct for this by calculating the weighted average of average spreads for each cell in a grid classified according to trade duration, where the weights are the trade frequencies by cell. ${ }^{9}$ The resulting spread estimates are slightly lower than the unweighted averages, but not by so much as to make those estimates seriously unreliable. We account for this bias in a rigorous parametric manner in the econometric analysis which discussed in Section VI.

Row 4: The realized spread, based on the tick test. The realized spread is defined as the absolute value of the difference between the trade price and the succeeding transactions price on the opposite side of the market. In row 4 of the table we use the standard tick test trade classification procedure proposed by Hasbrouck (1988) to determine trade directions. The realized spreads are very similar to the current nominal spreads reported in the second and third rows of the table. This realized spread is seen as declining from 1.82 index points in Period I to 1.39 index points in Period III, with some evidence of a slight increase in spread variability.

Row 5: The realized spread, based on the hybrid algorithm. This measure shows considerably narrower spreads, declining from 1.05 index points in Period I to 0.89 index points in Period III. The reason for the difference between this measure and that based on the

available, the resulting sample mean standard deviations are all tiny with respect to the differences in the sample means.

9 We define $J$ ranges ranked by trade duration and containing approximately equal numbers of transactions. For each range $j(\mathrm{j}=1, \ldots, J)$, let $n_{\mathrm{j}}$ be the number of trades and let $n=\Sigma n_{\mathrm{j}}$. Let $x_{\mathrm{j}}$ be the average spread in that range over trades for which this is calculated and $s_{\mathrm{j}}$ be the 
tick test is the high incidence in the dataset of quotes following transactions. Suppose, for example, quotes are at 5002 and 5004 giving a current spread of 2 points. Suppose an unambiguously identified public sale at the bid quote of 5002 is followed by an ask quote of 5002 and then a second transaction at the same price. Both the tick-test and the LR criterion will classify the second trade as a zero downtick sale, and will return a spread of 2 while our hybrid criterion will classify it as a purchase and will return a zero spread.

All realized spread measures relate to two distinct transactions, almost always undertaken by different traders, and possibly separated by significant time and hence information arrival, while the current spread relates to the quotes at a single point of time identified by a single trade. Traders will know the current spread at the time of trading, but they would be obliged to conjecture the realized spread.

These considerations reinforce our view that the effective spread measure is the most appropriate concept for analysis, where it can be calculated. We have therefore restricted the econometric analysis, reported in sections of this VI and VII, to the unweighted current nominal spread which should be completely secure, and have controlled for possible sample selection biases in the econometric estimation arising from the incomplete and possibly nonrandom sample resulting from the use of this measure. These measures all show an unambiguous narrowing of the spread following the move to CTS trading.

The calculated spread figures for Period II, which relate to the six weeks immediately following the move to the screen system, are intriguing. Depending which measure one takes, one can argue that spreads either widened (rows 2, 3 and 5), stayed broadly the same (row 4), or narrowed (row 1). ${ }^{10}$ The only clear conclusion for this learning period relates to spread variability which either increased (rows $1,2,3$ and 5 ) or remained constant (row 4). ${ }^{11}$

spread standard deviation. The weighted average spread $x$ and spread standard deviation $s$ over the entire sample are defined as $x=\Sigma n_{\mathrm{j}} x_{\mathrm{j}} / n$ and $s^{2}=\Sigma n_{\mathrm{j}} s_{\mathrm{j}}^{2} / \mathrm{n}$.

${ }^{10}$ Hill and Frino (2001), who claim a widening of the LIFFE spread, used a sample in which the post-automation period is weeks 3 to 12 of the post-automation period (i.e. they allow only a two week learning period). Unfortunately, they fail to give details of how they measured spreads, and it is possible that either their choice of sample or their spread measure may have resulted in what appear to be unrepresentative results.

${ }^{11}$ Gwilym and Thomas (1998) compared the spread on evening trading in bond futures on LIFFE using the screen APT system with the spread under open outcry during trading in the same markets in normal trading hours. They conclude that screen trading gives rise to significantly wider spreads than open outcry. In results not reported in this paper but available from the authors on request, we find that there was also narrowing of the spread in 
To summarize, the statistics reported in Table 2 show that, after a brief learning period, the move from open outcry to screen trading using the CONNECT system reduced spreads on the FTSE 100 futures contract, but may also have slightly increased their variability.

\section{Spread Determinants under Open Outcry and Computerized Trading}

Standard models relate bid-ask spreads to market makers' inventory holding costs, costs arising out of adverse selection and order processing costs. Inventory costs are seen as depending on the risk (variance and covariance) properties of the instrument, market makers' risk aversion and transaction size - see, for example, Stoll (1978). Adverse selection costs are seen as depending on the proportion of informed traders in the trading population, the variability associated with the information arrival process, and the price sensitivity of the instrument supply and demand schedules of the uninformed traders - see, for example, Copeland and Galai (1983). A number of authors have attempted decompositions of equity market spreads into these three components - see Glosten (1987), Glosten and Harris (1988), Stoll (1989) and George et al. (1991). In general terms, information and order processing costs are found to predominate in equities trading, but inventory effects assume greater importance in forex trading (Lyons, 1996). It seems likely that asymmetric information will be less important in index futures markets than in equities markets and our results are in line with this conjecture.

Both inventory and information theories predict that a high recent trading volume should widen the spread. In inventory theory, a high purchase by the public will reduce the dealer's inventory and force him to raise his ask price thereby widening the spread. This effect may be offset if he simultaneously raises his bid price but there may be little point in doing this if the market is temporarily dominated by purchase orders. In information theory, a high volume may signify an informed trade with the same implication for the spread, although informed traders will also try to imitate the trading volume characteristics of uninformed traders.

Period III relative to Period I in evening trading. However, there was less evidence of any change in spread variability. It is possible that lower liquidity in evening trading may account for the higher spreads reported by Gwilym and Thomas (1998). 
Information theory implies that the spread will depend on the proportion of informed traders in the market. This can never be directly observed but Theissen (2002) asserts as a "stylized fact" that volatility proxies for information asymmetry with the implication that volatility should be positively related to the spread. That claim is more persuasive in a crosssection of shares than in a time series on a single index futures contract. Furthermore, a positive volatility-spread relation is also implied by inventory theory since the cost of holding a portfolio other than the market portfolio depends on the asset volatility and the covariance of the asset with the market portfolio (Stoll, 1978). This is simply the futures volatility in the case of an index future.

The positive volatility-spread link is also implied if one can regard quoting as providing a free option to other market transactors since the value of an option will depend positively on the volatility of the underlying asset price process. This option interpretation has some validity in a screen system which supports a limit order book, but less in open outcry. The overall implication is that we should expect this link, and perhaps expect it to be stronger in screen trading, but that it does not constitute evidence in favour of one theory rather than the other.

Market liquidity may also affect the spread. We attempt to capture this effect by inclusion of inter-trade duration variables - the more rapid is trading, the higher will be liquidity and thus the lower the spread. That view implies a positive relationship between duration and the spread, and we should expect this to prevail under open outcry. In screen trading, this effect may be over-ridden by an opposing effect from the limit order book. When duration is very short, trades may push up the limit order book resulting in wider spreads until new limit orders are placed. This implies a negative relationship between duration and the spread. ${ }^{12}$

Standard expositions of both the information and inventory theories relate to a risk neutral market maker who makes zero profits. The NASDAQ "odd eighth" issue demonstrated that this paradigm is too simple (Christie and Schultz, 1994; Christie et al, 1994). In futures markets in which no trader is under an obligation to post limit orders (ie there are no designated market makers), it must be assumed that traders do this in the

\footnotetext{
${ }^{12}$ In earlier versions of this paper we also considered quote-trade durations. This duration measure is relevant if one considers a limit order to be analogous to an option. Inclusion of
} 
expectation of profit. As in all markets, margins are likely to be higher when competition is less intense. Domowitz and Steil (1999) have argued in the context of equities trading that screen trading increases market contestability. In futures trading, where contestability is less of an issue, the wide availability of trading terminals is likely to have increased the number of traders who have the possibility of unintermediated market access. In particular, it implies that more traders can post quotes. This motivates us to measure competitive pressure by the ratio of quotes to trades in recent trading. ${ }^{13}$

We use tick regression models to examine spread determinants. Tick regressions fully exploit the available information but are subject to potential sample selection bias due the fact that the spread is only measured over a possibly non-random subset of observations. Spreads are measured using the current nominal spread measure discussed in sections IV and V, which we argue is equivalent, in our dataset, to an effective spread. Recall that this measure is available for less than $50 \%$ of all trades, so a potential sample selection problem arises. We use the following regressor variables:

- Spreads lagged by a single trade $s_{\mathrm{i}-1}$ (the spread on the most recent trade for which a spread was measurable) by two trades $s_{\mathrm{i}-2}$ (the second most recent trade for which a spread can be calculated) and the average $s_{\mathrm{i}(-3,-25)}$ over the previous 25 trades for which the spread is measurable excluding the first two. These variables are included to reflect evidence of slow decay in the spread lag distributions.

- $\log$ trading volume with the sane lag structure $\left(\ln V_{\mathrm{i}-1}, \ln V_{\mathrm{i}-2}, \ln V_{\mathrm{i}(-3,-25)}\right)$.

- The number of trades $c o m_{\mathrm{i}}$ in any multiple transaction (Period III only). We include this variable to control for the possible effects arising from our aggregation of trades with the same time-stamp.

both inter-trade and quote-trade duration measures makes it difficult to interpret the resulting estimates.

${ }^{13}$ It has been suggested to us that this variable may be affected by design features of the trading environment. We acknowledge this possibility but note that while the criticism may be valid for comparisons across the open outcry and screen regimes it does not apply within either regime. Our regression results are therefore valid but comparison of coefficients across the regimes may require qualification. If we had information on the size of the limit order book, or, if there were some way of circumventing trader anonymity, it might be possible to construct a superior measure of market power, e.g. a Herfindahl index of trader concentration - see McInish and Wood (1992). 
- Volatility $\sigma_{i}$, measured as the (square root of the) conditional variance from a $\operatorname{GARCH}(1,1)$ model estimated on the complete sample of tick data, ${ }^{14}$ and volatility interacted with lagged trading volume $\sigma_{\mathrm{i}} \mathrm{x} \ln V_{\mathrm{i}(-3,-25)}$;

- Inter-trade duration, measured as the time in seconds between successive trades, ${ }^{15}$ with the same lag structure as spreads and trading volume $\left(\ln D_{\mathrm{i}-1}, \ln D_{\mathrm{i}-2}, \ln D_{\mathrm{i}(-3,-25)}\right)$.

- Trading activity qtratio $_{\mathrm{i}-1}$ which measures the number of quotes made in the period defined by the 25 trades prior to trade $i$. This variable may be interpreted as a measure of competitive pressure.

- The Heckman (1979) sample selectivity correction factor $\lambda_{\mathrm{i}}$ (see below).

It is well known that high frequency data exhibit substantial intra-daily (or diurnal) seasonality - see Engle (2000). Failure to account for these effects can result in biased coefficient estimates. These seasonal patterns appear more acute for the Period I regressions than those run for Period III. We control for this by running the regressions with and without a set of diurnal seasonal dummies, seventeen in the Period I regressions but only six in the Period III regressions where the diurnal effects are smaller. Although diurnal effects are present in the data, these only appear to substantially distort the coefficient estimates in relation to the initial thirty minutes of open outcry trading (Period I) when trading was very thin. We therefore omit the relatively small number of observations $(10,533)$ relating to this

${ }^{14}$ See Engle (1982). The mean process is specified as $\Delta p_{i}=\mu+\beta s_{i} \cdot \Delta z_{i}+\varepsilon_{i}$ where $s_{\mathrm{i}}$ is the current spread and $z_{\mathrm{i}}$ is the buy-sell indicator. It is important to control for variations in the spread since otherwise these dominate the estimated conditional volatility. The equation is specified in levels and not logarithms reflecting the fact that the price changes is a (typically small) integer number of ticks. In cases in which the current spread is not observed, we replace it by its most recently observed value. In cases in which the trade direction was not classified for either the current or the previous trade, we set $\Delta z_{\mathrm{i}}=0$. The subsequent spread regression results are insensitive to changes in these latter measurement conventions. We investigated inclusion of diurnal (time of day) dummies in the volatility regression but concluded that these made little difference to the filtered volatility estimates. Details of the GARCH estimates are available from the authors on request.

${ }^{15}$ Where two trades are recorded with the same time stamp but are on opposite sides of the market, we impute a duration of $1 / 3$. Write $x$ and $y$ for the two unobserved consecutive trade times measured relative to the previous integer number of seconds, and suppose trades are uniformly distributed over the one second interval. If trade $x$ occurs first, the expected duration between it and trade $y$ is $\int_{0}^{1} \int_{x}^{1}(y-x) d y d x=\frac{1}{6}$, and similarly if trade $y$ is first. Since each possibility is equally likely, the average duration between trades is $1 / 3$. 
early morning trading period - see also Copeland et al. (2004). In what follows, we only report estimates from the equations which omit the diurnal dummies. Comparable estimates for the equations containing the dummies are available on request.

As noted, the spread regressions we report depend on an endogenously determined sample, and the estimates are therefore susceptible to sample selection bias. We correct for possible sample selection problems, arising from exclusion of trades for which we do not have the information to calculate the spread with confidence, by using Heckman's (1979) procedure. Taking the entire sample, we define the variable $y_{\mathrm{i}}$ by $y_{i}=\left\{\begin{array}{ll}1 & \text { if } i \in S \\ 0 & \text { if } i \notin S\end{array}\right.$ where $S$ is the sample over which the spread is available. The Heckman procedure requires estimation of a preliminary probit $\operatorname{Pr}\left(y_{i}=1\right)=\Phi\left(\beta^{\prime} x_{i}\right)$ where $\Phi($.$) is the standard normal distribution$ function, $x_{\mathrm{i}}$ is a vector of explanatory variables and $\beta$ is a vector of unknown coefficients (results not reported). For simplicity, the probit regressor variables are identical to those in the subsequent regression. On the basis of the estimated probit, we may calculate the inverse Mills' ratio $\lambda_{i}=\frac{\phi\left(\hat{\beta} x_{i}\right)}{\Phi\left(\hat{\beta} x_{i}\right)}$ where $\phi($.$) is the standard normal density and a circumflex indicates$ an estimate. Inclusion of the vector $\lambda$ of inverse Mills' ratios in the spread regressions eliminates potential sample selection bias. ${ }^{16}$

Regression results are reported in Table 3. The general features of the estimated regressions are as follows:

- Spreads remain positively autocorrelated even when conditioned on other variables. The dependence is higher under screen trading than open outcry. (The sum of the lagged spread coefficients is 0.341 in Period I and 0.514 on Period III.)

- High volume does appear to increase the spread. Volume effects are larger in Period III than in Period I, and largest of all in Period II. We believe this reflects the fact that high volume eliminates a greater number of quotes from the limit order book. Volume effects are also apparent in the consistently significant and positive coefficients on the combined trades variable in the Period II and III regressions.

16 The procedure assumes joint normality of the disturbances on the spread and sample selection equations. With a common set of explanatory variables, identification depends on the nonlinearity of the inverse Mills' ratio in terms of these variables. 
- Spreads are strongly positively related to volatility in both regimes. ${ }^{17}$ The size of this effect appears largely independent of the regime. This might be taken as evidence that the impact of volatility on spreads arises out of traders' risk preferences rather than the trading mechanism. The interacted volume-volatility terms are strongly negative in the Period II and III regressions with a smaller and less consistent negative effect apparent in Period I. Interpreting high volume as an indicator of high liquidity, this indicates that, in screen trading, the impact of high volatility, discussed above, is attenuated in periods of high liquidity.

- The liquidity impact of inter-trade trade duration is apparent in the Period I regressions, where this effect is positive and significant. Low liquidity (high durations) is associated with wider spreads. This effect is also evident in the third of the estimated duration coefficients in the Period III regression. However, order book effects over-ride the liquidity effect in relation to the current and single lagged duration coefficients in that regression and in the Period II regression.

- Quotation pressure is seen as exerting downward pressure on spreads. This effect is broadly comparable in Periods I and III but is higher in Period II.

- The Heckman selection parameter shows no selection bias in Period I but is significant in Periods II and III.

There are many elements of consistency between the estimated spread equations under open outcry and screen trading but also a number of important differences. The strongest element of consistency are in the estimated effects of volatility and liquidity (as reflected in inter-trade duration) on the spread. The most important difference relates to the effects of the limit order book, which increases the positive impact of high trading volume on the spread. This might suggest that depth is lower in the screen market. We investigate this issue in section VII. The second important difference is that the spread appears more predictable over short periods of time under screen trading as reflected in the autoregressive coefficients. We do not offer any explanation for this change. Finally, the positive

\footnotetext{
${ }^{17}$ For period III this is true in the volume range below 30 contracts, at which the majority of the trades take place. In the higher volume range the relationship between volatility and volume is absent. The negative coefficient of the cross variable volatility $\times$ volume accounts for this.
} 
relationship between volatility and the spread is much more radically attenuated by high liquidity in screen trading.

In section $\mathrm{V}$, we showed that the LIFFE bid-ask spread has narrowed over the period that the market has moved from open outcry to screen trading. We are now in a position to analyze the origin of this change. Averaging over the entire set of transactions used in the tick regressions reported in Table 3, the spread narrowed by 0.37 index points from 1.74 to 1.37 points. These numbers are in line with the current nominal spreads given in the second and third rows of Table 2, with the small differences reflecting the larger number of observations excluded in the econometric estimation samples.

Write the solved (static) versions of the regressions reported in Table 3 as

$$
s^{\ell}=\sum_{j=1}^{k} \theta_{j}^{\ell} x_{j}^{\ell} \quad(\ell=1,2,3)
$$

where the superscript $(1,2,3)$ refers to Periods I, II and III values respectively. ${ }^{18}$ Columns 1 and 2 of Table 4 decompose the change in the spread between the two samples of screen trading and the open outcry sample $\Delta_{m} \bar{s}=\bar{s}_{m}-\bar{s}_{1}(m=2,3)$ into six components.

Consider first the comparison between Periods III and I (Table 4, column 2). The narrowing of the spread is largely attributable to the volatility and competitive pressure variables. This impact is offset by the effects of order splitting as large transactions eat into the limit order book. Volume and liquidity effects appear relatively small. We do not directly measure order processing costs, but any major change in this component should be reflected in the residual component which is also small. ${ }^{19}$

Turning to the comparison between Periods II and I (Table 4, column 1), where the overall change in spreads was much smaller, we again see large negative competitive pressure effects but the volatility effect is small and positive. There is also a positive volume effect on spreads.

18 The $\theta$ coefficients are the estimated coefficients from columns 1,3 and 5 of Table $\mathrm{V}$ divided by one minus the sum of the coefficients of the three lagged spread variables.

19 In performing this analysis, we have attributed the volatility-volume interaction to the volatility term. The residual picks up the effects of the intercept and the inverse Mills' ratio, which is a correction for a non-zero expected value for the equation error. The small approximation error arises because the sampling selection process induces differences between the means of the same variable at different lags. 
We may extend this framework to ask whether the changes in the spread are attributable to changes in the average values of the variables entering into the spread equation or a change in the equation coefficients. Following Blinder (1973) and Oaxaca (1973), we may rearrange equation (1) as ${ }^{20}$

$$
\Delta_{m} \bar{S}=\sum_{j=1}^{k} \theta_{j}^{1}\left(\Delta_{m} \bar{x}_{j}\right)+\sum_{j=1}^{k}\left(\Delta_{m} \theta_{j}\right) \bar{x}_{j}^{m} \quad(m=2,3)
$$

The first set of terms in equation (2) gives the changes in the average spread attributable to changes in the sample means of the regressor variables ("input changes"), while the second set of terms give the changes attributable to changes in coefficients ("structural changes").

Decomposition results are given in the final four columns of Table $4 .^{21}$ The broad qualitative conclusion in either case is that the volatility effect on the spread, which dominates the Periods III/I comparison, is, in the first instance, due more to lower levels of volatility than to any structural change, while the effects of competitive pressure, important in both comparisons, appear largely structural. Volume effects are attributed to both input and structural changes. These tend to be offsetting in the III/I comparison but the adverse structural effect dominates in the II/I comparison.

These decomposition results suggest that, after an initial learning period which may have been associated with reduced market depth, the narrowing of the LIFFE spread was attributable to the fact that the screen trading system facilitates competition between traders, and that it is associated with a lower level of noise. The effects of competition were anticipated by Pirrong (1996) who suggested that open outcry trading might be more vulnerable to collusion than screen trading, but we are not aware of previous systematic empirical evidence supporting this claim.

Our volatility results offer support for the view that the limit order book gives improved price discovery. It is reasonable to regard high frequency volatility as reflecting trading noise, while volatility at lower frequencies reflects the fundamentals-driven information arrival process. Our estimate of the GARCH tick volatility declines sharply from 1.53 index points in Period I to 0.98 index points in Period III, but price change standard

${ }^{20}$ Alternatively (but not equivalently) $\Delta_{m} \bar{s}=\sum_{j=1}^{k} \theta_{j}^{m}\left(\Delta_{m} \bar{x}_{j}\right)+\sum_{j=1}^{k}\left(\Delta_{m} \theta_{j}\right) \bar{x}_{j}^{1} \quad(m=2,3)$

The decompositions based on this equation, available from the authors on request, are qualitatively similar to those reported in Table 4. 
deviations calculated at one and five minute frequencies show much smaller falls. The major component of the fall in tick volatility therefore relates only to very high frequency price movements. This appears a productive topic for further research.

\section{Adverse Selection and Market Depth}

Market depth is the inverse of price impact. Institutional investors, who will frequently wish to trade in large size, will be as much concerned with depth as with spreads. It is therefore important to establish whether the move to screen trading has affected depth, and if so, in what way.

There are no theoretical reasons for supposing that a lower spread under one system or the other necessarily implies superior market depth except in so far as lower spreads might increase depth indirectly via an increased trade volume. However, it is reasonable to expect spreads and depth to have the same determinants. Comparing the LIFFE open outcry and DTB CTS bund futures contracts, Pirrong (1996) argued that the DTB exhibited greater depth. In this section, we examine whether this finding extends to the LIFFE FTSE futures market over the switch to screen trading.

Unlike spreads, market depth can only be directly observed from data on the full limit order book, and hence not at all under open outcry. In the absence of limit order book data, depth may be inferred from transactions data. Roll (1984) suggested an indirect measure of the effective spread $s$ by supposing that transaction price $p_{\mathrm{i}}$ is related to the unobserved fundamental value $v_{\mathrm{i}}$ by the equation

$$
p_{i}=v_{i}+\frac{s}{2} z_{i}
$$

where $z_{\mathrm{i}}$ is the buy-sell indicator defined as +1 for a purchase and -1 for a sale. Roll used this equation to estimate effective spreads from the covariance of adjacent transaction prices. If trade patterns are uninformative and the fundamental value evolves as

$$
\Delta v_{i}=\varepsilon_{i}
$$

where $\varepsilon_{\mathrm{i}}$ is unpredictable from information prior to trade $i$, the price evolves as

$$
\Delta p_{i}=\frac{s}{2} \Delta z_{i}+\varepsilon_{i}
$$

${ }^{21}$ These decompositions do not imply any causal link - see Berndt (1991, ch.5). 
George et al (1991) extended Roll's framework by supposing that the effective spread is influenced by trade size $\ln V_{\mathrm{i}}$ so that $s_{\mathrm{i}}=2\left(\gamma_{0}+\gamma_{1} \ln V_{\mathrm{i}}\right)$. We further suppose that price signals are informative about market fundamentals in proportion to market volatility so that $\Delta v_{i}=\sigma_{i} \varepsilon_{i}$. This is reasonable if one supposes that news either enhances or resolves market uncertainty. With these modifications, equation (5) becomes

$$
\frac{\Delta p_{i}}{\sigma_{i}}=\beta_{0}+\sum_{j=1}^{k} \beta_{j}\left(\frac{\Delta p_{i-j}}{\sigma_{i-j}}\right)+\gamma_{0}\left(\frac{s_{i}}{\sigma_{i}}\right) \Delta z_{i}+\gamma_{1}\left(\frac{s_{i}}{\sigma_{i}}\right) \ln V_{i} \Delta z_{i}+\varepsilon_{i}
$$

where we have also added an intercept and a distributed lag of past price changes - see the price return equations in Hasbrouck (1991) and Hasbrouck and Sofianos (1993). In equation (6), the coefficient $\gamma_{1}$ measures the price impact of the trade on the original transactor, and is therefore a measure of market depth - the lower $\gamma_{1}$, the greater market depth. Market depth is the inverse of market impact - the number of contracts which will move the price by one unit.

If market makers face adverse selection, trade direction $z_{\mathrm{i}-1}$ may be informative. To account for this possibility, we modify equation (4) as

$$
\frac{\Delta v_{i}}{\sigma_{i}}=\alpha_{0} z_{i-1}+\alpha_{1} \ln V_{i-1} z_{i-1}+\alpha_{2} \ln D_{i-1} z_{i-1}+\varepsilon_{i}
$$

where we have also allowed this effect to interact with volume and duration. We also allow the spread to depend on duration, as a liquidity measure in line with the results reported in section 5 writing $s_{\mathrm{i}}=2\left(\gamma_{0}+\gamma_{1} \ln V_{\mathrm{i}}+\gamma_{2} \ln D_{\mathrm{i}}\right)$. Equation (6) therefore generalizes to

$$
\begin{aligned}
& \frac{\Delta p_{i}}{\sigma_{i}}=\beta_{0}+\sum_{j=1}^{k} \beta_{j}\left(\frac{\Delta p_{i-j}}{\sigma_{i-j}}\right)+\gamma_{0}\left(\frac{s_{i}}{\sigma_{i}}\right) \Delta z_{i}+\gamma_{1}\left(\frac{s_{i}}{\sigma_{i}}\right) \ln V_{i} \Delta z_{i} \\
& +\gamma_{2}\left(\frac{s_{i}}{\sigma_{i}}\right) \ln D_{i} \Delta z_{i}+\alpha_{0} z_{i-1}+\alpha_{1} \ln V_{i-1} z_{i-1}+\alpha_{2} \ln D_{i-1} z_{i-1}+\varepsilon_{i}
\end{aligned}
$$

Equation (8) gives a marginally superior explanation but is more difficult to interpret.

Estimation results for equation (6) are given in columns 1 (Period I), 3 (Period II) and 5 (Period III) of Table 5 and those for equation (8) appear in columns 2, 4 and 6 of the same table. ${ }^{22}$ We follow the Heckman procedure for the Period I regressions where the buy-sell indicator is not available for a substantial proportion of the sample, but rely on least squares for Periods II and III where there are very few missing observations. Despite being

${ }^{22}$ Estimates are given of the equations which omit the diurnal dummies. Estimates which include these dummies are qualitatively similar and are available from the authors on request. 
significantly different from the theoretical value of $1 / 2$, the estimated $\gamma_{0}$ coefficients are fairly close to this value in a quantitative sense. Lagged volume in seen as increasing price impact under both open outcry and screen trading (columns 2, 4 and 6). The positive $\gamma_{1}$ volume interaction coefficient supports the view that large volumes result in wider realized spreads. The statistically significant $\gamma_{2}$ duration interaction with the buy-sell indicator in Period II and III shows price impact increasing at low levels of liquidity, consistent with theory.

The significant $\alpha_{0}$ coefficients show that trade direction clearly is informative, dramatically so in screen trading and in the learning period. This is evidence that informational-based trading is indeed important. However, the estimated $\alpha_{0}$ coefficient is lower in Period III, compensated by higher coefficients for (interacted) lagged log volume and duration. Adverse selection in the screen market appears to be related to large trades and to trades during quiet periods. At the sample means for volume and duration, the overall adverse selection is slightly lower in Period III. This is consistent with the results of Coppejans and Domowitz (1999) in relation to trading in the CME S\&P 500 contract.

In order to obtain a better handle on price impact in the screen trading regime, we focus on those trades identified as having been split by the trading algorithm. There are 11,025 such trades in Period II and 143,422 in Period III. For these trades, we can see the price of each component. We define a price impact variable as the absolute value of the difference between the average price at which the trade was completed and the price of the initial element of the trade, and relate this to the trade volume, its square (in order to analyze whether the relationship is linear), the number of distinct trades into which the combined trade appears to have been split (components) and also, as controls, the lagged spread, volatility and duration variables included in the spread regressions reported in Table 3.

The estimates of this regression are reported in Table 6 . The estimated coefficients are similar to those in the spread regression reported in the third column of Table 3. Price impact rises with volume, flattening out of the relationship at volumes higher than those normally traded. (The Period III quadratic has a turning point at 280 contracts and that for Period II at 630 contracts). The effect of pushing into the limit order book is clear from the significant coefficient on the number of limit orders taken up - each additional order costs, on average, nearly four index points in Period III, and five index points in Period II suggesting that traders may have been unfamiliar with use of the order book at the start of screen trading. 
This effect is much stronger than the volume effect. Price impact is more severe when volatility is high, when the spread is wide and when liquidity (as measured by trade duration) is low.

The estimates reported in Table 6 indicate that it is not volume as such which causes price impact, but splitting against multiple quotes. So long as one can trade against a single quote, the screen spread is narrower than that which was available under open outcry, but this advantage can be lost through a single move into the limit book. The statistics in Table 1 show that volume per trade declined from twelve contracts under open outcry to four contracts with LIFFE CONNECT. This suggests a substantial reduction in depth with the implication that firms need to trade more actively under the screen system if they are to transact comparable volumes to those undertaken in the open outcry regime. Traders who require immediacy may find that they pay significantly more under screen trading if they are forced to move into the limit order book. The fact that they choose to do this implies that they are willing to bear that cost.

\section{Conclusions}

The May 1999 change in trading system at the London financial futures exchange, LIFFE, provides an opportunity to assess the difference between open outcry and screen trading. This move is of major interest to exchanges in other financial centres, particularly in the United States, where similar changes are in progress. In this paper, we have looked at the impact of the change on the liquid UK FTSE 100 index futures contract. An advantage of considering the effects of computerized trading on a futures market is that a number of technical problems arising out of interpretation of the tick data appear much less acute than with comparable equities market data.

A crucial difference between screen trading and open outcry is that the former permits the operation of a limit order book. Open outcry markets effectively lack memory. The consequence is that effective spreads evolve in a different way in the screen market relative to the earlier open outcry market. The change in trading system has also resulted in an increase in the variability of the spread, both on an inter-day and intra-day basis. This change does appear to us to be directly attributable to the change in trading system (the variability of the evening spread declined over the same period) and is a consequence of the operation of 
the limit order book. This implies that a trade will widen the spread if it takes out all the limit orders at the currently best price on one or other side of the market.

The bid-ask spread is the most standard measure of trading costs. Advocates of change argue that a CTS should reduce spreads. Against this, it has been suggested that the greater anonymity offered by computerized trading systems might increase adverse selection, which would imply an increase in spreads. We find that, after an initial learning period, the spread on the LIFFE FTSE contract has unambiguously narrowed over the period of the change (by around 20\%). Regression analysis attributes the narrowing of the spread to increased competitive pressures and a decline in tick-level price volatility. Our estimates support the view that increased competitive pressure, measured by the excess of quotes (limit orders in the screen system) over trades, has a larger negative impact on spreads under screen trading than open outcry. Subject to qualifications on imperfect measurement of this competitive effect, we believe this is due to the fact that more traders now have direct access to the market.

Volatility is the most important single determinant of the spread under in open outcry and screen trading systems. The impact of volatility in explaining the narrowing of the spread comes primarily through a lower tick level volatility rather than through the effect of any specified level of volatility on the spread. We conjecture that the decline in tick level volatility, which only occurred after the learning period, is the result of the superior price discovery arising out of the limit order book.

We do not find evidence suggesting a decline in transaction processing costs. However, in the absence of direct measures of these costs, that conclusion is tentative. Adverse selection costs appear to be slightly lower in the screen regime with the qualification that large trades and trades made during periods of low activity are particularly informative.

Market impact is different under the open outcry and screen trading systems. Because CTS's give traders information on the limit order book, they can estimate market impact in advance of trading, and decide whether they are willing to bear this cost. Large trades are therefore seen to push into the limit order book. Under open outcry traders were obliged to choose between making quotes and responding to others' quotes. In the former case, it would not generally be wise to announce the size of trade one wished ultimately to complete, while in the latter case, the trader was constrained to a maximum of the amount the counterparty was offering to buy or sell. Our estimates suggest that price impact of a large market order in 
the screen regime depends on the number of limit orders against which it trades rather than on its volume per se. But although the introduction of a limit order book has changed the way depth price impact manifests itself in the market, we do not find any evidence that the move to screen trading has substantially altered the depth of the LIFFE FTSE 100 market.

Arguments about whether exchanges should or should not automate tend to focus on whether CTS's can achieve the same liquidity as open outcry markets. This is a difficult question to answer in a categorical manner because of the absence of any precise and comprehensive measure of liquidity. One may think of liquidity as comprising tightness (the spread) and depth. Our analysis suggests that both are determined in different ways under the different trading systems. In this particular instance, the move to screen trading does appear to have been associated with a narrowing of the spread, resulting in a tighter market, while at the same time market depth appears unaffected. But it is possible that different results would obtain in a market where the possibility of private information may result in adverse selection being a more serious concern.

Within the context of futures trading, the most important aspects of screen trading are the opportunity for more active competition between traders, the decline in high frequency price volatility and the introduction of the limit order book facility. Increased competition and reduced high frequency volatility appear to have driven the narrowing of the spread, with the volatility reduction perhaps resulting from the increased transparency of the limit order book. 


\section{References}

Berndt, E.R. (1991), The Practice of Econometrics, Reading (Mass.), AddisonWesley.

Blennerhassett, M., and R.G. Bowman (1994), "A change in market microstructure: the switch to electronic trading on the New Zealand Stock Exchange", Journal of International Financial Markets, Institutions and Money, 8, 261-76.

Blinder, A.S. (1973), "Wage discrimination: reduced form and structural estimates", Journal of Human Resources, 18, 436-55.

Christie, W., and P. Schultz (1994), "Why do NASDAQ market makers avoid oddeighth quotes?", Journal of Finance, 49, 1813-40.

Christie, W., J. Harris and P. Schultz (1994), "Why did NASDAQ market makers stop avoiding odd-eighth quotes?”, Journal of Finance, 49, 1841-60.

Copeland, T., and D. Galai (1983), "Information effects and the bid-ask spread", Journal of Finance, 38, 1457-69.

Copeland, L., K. Lam and S-A. Jones (2004), "The index futures markets: Is screen trading more efficient?", Journal of Futures Markets, 24, 337-57.

Coppejans, M., and I. Domowitz (1999), "Pricing behavior in an off-hours computerized market", Journal of Empirical Finance, 6, 583-607.

Degryse, H. and M. Van Achter (2001), "Alternative trading systems and liquidity", paper prepared for $23^{\text {rd }}$ SUERF Colloquium, Katholiek Univesiteit Leuven.

Domowitz, I. (2001), "Liquidity, transactions costs and reintermediation in electronic markets", eBusiness Research Center Working Paper 4-2001, Penn State University.

Domowitz, I., and B. Steil (1999), "Automation, trading costs and the structure of the securities trading industry", Brookings-Wharton Papers on Financial Services, 2, 33 92.

Ellis, K., R. Michaely, and M. O'Hara (2000), “The accuracy of trade classification rules: evidence from Nasdaq", Journal of Financial and Quantitative Analysis, 35, 529-51.

Engle, R.F. (1982), "Autoregressive conditional heteroskedasticity with estimates of the variance of UK inflation", Econometrica, 50, 987-1008.

Engle, R.F. (2000), "The econometrics of ultra-high frequency data", Econometrica, 68, 1-22.

Finucane, T.J. (2000), "A direct test of methods for inferring trade direction from intra-day data", Journal of Financial and Quantitative Analysis, 35, 553-76. 
Fremault Vila, A., and G. Sandmann (1996), "Floor trading versus electronic screen trading: an empirical analysis of market liquidity in the Nikkei stock index futures market", Financial Markets Group Discussion Paper 218, London School of Economics.

Franses, P.H., R. van Leperen, P. Kofman, M. Martens and B. Menkveld (1997), "Volatility transmission and patterns in bund futures", Journal of Financial Research, 20, 459-82.

Frino, A., T. McInish and M. Toner (1994), "The liquidity of screen exchanges: new evidence from German bund futures", Journal of International Financial Markets, Institutions and Money, 8, 225-41.

George, T.J., G. Kaul and M. Nimalendran (1991), "Spread and its components: a new approach", Review of Financial Studies, 4, 623-56.

Glosten, L., and P. Milgrom (1985), "Bid, ask and transactions prices in a specialist market with heterogeneously informed traders", Journal of Financial Economics, 13, 71-100.

Glosten, L. (1987), "Components of the bid/ask spread and the statistical properties of transactions prices”, Journal of Finance, 42, 1293-307.

Glosten, L., and L. Harris (1988), "Estimating the components of the bid-ask spread", Journal of Financial Economics, 21, 123-42.

Grossman, S., and M. Miller (1986), "The economic costs and benefits of the proposed one-minute time bracketing regulation", Journal of Futures Markets, 6, 14166 .

Grünbichler, A., F. Longstaff and E. Schwartz (1994), "Electronic screen trading and the transmission of information: an empirical investigation", Journal of Financial Intermediation, 3, 166-87.

Gwilym, O. ap, and E. Alibo (2003), "Decreased price clustering in FTSE100 contracts following a transfer from floor to electronic trading", Journal of Futures markets, 23, 647-759.

Gwilym, O. ap, and S. Thomas (1998), "The influence of electronic trading on bidask spreads: new evidence from European bond futures", Journal of Fixed Income, 719.

Hasbrouck, J. (1988), "Trades, quotes, inventories and information", Journal of Financial Economics, 22, 229-52.

Hasbrouck, J. (1991), "Measuring the information content of stock trades", Journal of Finance, 46, 179-207.

Hasbrouck, J. and G. Sofianos (1993), "The trades of market makers: an empirical analysis of NYSE specialists", Journal of Finance, 48, 1565-94. 
Heckman, J. (1979), "Sample selection bias as a specification error", Econometrica, 47, 153-61.

Hill, A.M. and A. Frino (2001), "The impact of electronic trading on liquidity", http://ssrn.com/abstract $=269419$

Kofman, P., and J. Moser (1996), "Spreads, information flows and transparency across trading systems", Applied Financial Economics, 7, 281-94.

Kopeland, L., K. Lam and S-A. Jones (2004), "The index futures market: Is screen trading more efficient?", Journal of Futures Markets, 24, 337-57.

Lee, C.M.C., and M.J. Ready (1991), "Inferring trade direction from intraday data", Journal of Finance, 46, 733-46.

LIFFE (2001), LIFFE CONNECTTM Trading Procedures, http://www.liffe.com .

Lyons, R.K. (1996), "Foreign exchange volume: sound and fury signifying nothing?", in Frankel, J., and G. Galli, eds., The Microstructure of Foreign Exchange Markets, Chicago, University of Chicago Press.

Massimb, M.N., and B.D. Phelps (1994), "Electronic trading, market structure and liquidity", Financial Analysts Journal, 50, 39-50.

McInish, T., and R. Wood (1992), "Competition, dispersion of trading and market performance”, Working Paper, University of Memphis.

Miller, M.H. (1990), "International competitiveness of U.S. futures exchanges", Journal of Financial Studies Research, 4, 387-408.

Miller, M.H, (1991), Financial Innovation and Market Volatility, Oxford, Blackwell.

Naidu, G.N., and M. Rozeff (1994), "Volume, volatility, liquidity and efficiency of the Singapore Stock Exchange before and after automation", Pacific-Basin Finance Journal, 2, 23-42.

Neal, R. (1992), "A comparison of transaction costs between competitive market maker and specialist market structures", Journal of Business, 65, 317-34.

Oaxaca, R. (1973), "Male female wage differentials in urban labor markets", International Economic Review, 14, 693-709.

Petersen, M., and D. Fialkowski (1994), "Posted versus effective spreads: good prices or bad quotes", Journal of Financial Economics, 50, 231-52.

Pirrong, C. (1996), "Market liquidity and depth on computerized trading systems: a comparison of DTB and LIFFE bund contracts", Journal of Futures Markets, 16, 51943. 
Roll, E. (1984), "A simple implicit measure of the effective bid-ask spread in an efficient market", Journal of Finance, 39, 1127-40.

Shyy, G., and J.H. Lee (1995), "Price transmission and information asymmetry in bund futures markets: LIFFE vs. DTB”, Journal of Futures Markets, 15, 87-99.

Stoll, H. (1978), "The supply of dealer services in securities markets", Journal of Finance, 33, 1133-51.

Stoll, H. (1989), "Inferring the components of the bid-ask spread: theory and empirical tests", Journal of Finance, 44, 115-34.

Taylor, N., D. van Dijk, P.H. Franses and A. Lucas (2000), "SETS, arbitrage activity and stock price dynamics", Journal of Banking and Finance, 24, 1289-1306.

Theissen, E. (2002), "Floor versus screen trading: evidence from the German stock market", Journal of Institutional and Theoretical Economics, 158.

\section{Appendix: LIFFE CONNECT TM}

Since May 1999, LIFFE has operated the LIFFE CONNECT ${ }^{\mathrm{TM}}$ trading system. Details of the current implementation of the trading system are given in LIFFE (2001). The following is a brief précis of the most important features of the system:

1. Order Types: Orders are either limit orders or market orders. Limit order are executed at the price stated or better. In the absence of a specific instruction to the contrary, residual volumes are retained on the order book until executed. Market orders are executed at the best price available until all volume has been traded. In the absence of any designation, orders are treated as limit orders.

2. Order Duration: Orders (whether limit orders or market orders) may be designated either Good 'Til Cancelled (GTC) or Immediate or Cancel (IC), and either Complete Volume or Minimum Volume (MV). Market orders are automatically designated IC unless otherwise specified. GTC orders remain on the system until they are withdrawn, or market close, or expiry of the contract in question (which ever occurs first).

3. Priority: Priority is best price followed by oldest time stamp. A buy order at the highest price and a sell order at the lowest price has priority over other orders in the same contract month. Contracts may be designated by the Exchange as pro rata. For pro rata contracts, all buy orders at the highest price and all sell orders at the lowest price in the same contract month are traded in accordance with a pro-rata algorithm. For all other contract, buy/sell orders at the best price will trade in order according to the time they were accepted by the trading system.

4. Uncrossing: If, at market opening there is backwardation (bids higher than offers), an uncrossing algorithm is used to calculate the price at which the maximum volume can be traded. Any orders executed in this way will be traded at a price equal to or better than that at which they were entered and any untraded bids and/or offers will remain in the market. 


\begin{tabular}{|l|l|c|c|}
\hline \multicolumn{5}{|c|}{ Table 1 } \\
\hline \multicolumn{5}{|c|}{ Trading Volumes under Open Outcry and Screen Trading } \\
\hline \multicolumn{2}{|c|}{$\begin{array}{c}\text { open } \\
\text { outcry/APT }\end{array}$} & \multicolumn{2}{c|}{ screen trading } \\
(LIFFE CONNECT)
\end{tabular}

\begin{tabular}{|c|c|c|c|}
\hline \multicolumn{4}{|c|}{$\begin{array}{c}\text { Table } 2 \\
\text { Summary Statistics, Bid-Ask Spreads (index points, normal trading hours) }\end{array}$} \\
\hline & Open Outcry & \multicolumn{2}{|c|}{ Screen Trading } \\
\hline & Period I & Period II & Period III \\
\hline Average nominal spread & $\begin{array}{c}2.21 \\
(1.12) \\
25161\end{array}$ & $\begin{array}{c}2.10 \\
(1.45) \\
2712\end{array}$ & $\begin{array}{c}1.81 \\
(1.14) \\
30648\end{array}$ \\
\hline $\begin{array}{l}\text { Current nominal spread (unweighted) } \\
\text { (equivalent to effective spread) }\end{array}$ & $\begin{array}{c}1.76 \\
(0.87) \\
215698\end{array}$ & $\begin{array}{l}1.86 \\
(1.65) \\
49270\end{array}$ & $\begin{array}{c}1.47 \\
(0.98) \\
833029\end{array}$ \\
\hline Current nominal spread (weighted) & $\begin{array}{c}1.68 \\
(0.81) \\
215698\end{array}$ & $\begin{array}{l}1.85 \\
(0.80) \\
49270\end{array}$ & $\begin{array}{c}1.43 \\
(1.02) \\
833029\end{array}$ \\
\hline Realized spread, based on tick test & $\begin{array}{c}1.82 \\
(1.08) \\
177387\end{array}$ & $\begin{array}{c}1.81 \\
(1.68) \\
35996\end{array}$ & $\begin{array}{c}1.39 \\
(1.15) \\
570100\end{array}$ \\
\hline $\begin{array}{l}\text { Realized spread, using both quote- } \\
\text { and tick-based criteria }\end{array}$ & $\begin{array}{c}1.05 \\
(1.44) \\
142923\end{array}$ & $\begin{array}{l}1.14 \\
(1.71) \\
42763\end{array}$ & $\begin{array}{c}0.89 \\
(1.15) \\
700420\end{array}$ \\
\hline \multicolumn{4}{|c|}{$\begin{array}{l}\text { The table reports the average spread (index points) on each measure for each sample with } \\
\text { the standard deviation in parentheses. We also give the number of observations on which } \\
\text { these statistics are based. Average nominal spread is sampled at five minute intervals. The } \\
\text { current nominal spread is averaged over all trades at which the spread can be determined. } \\
\text { The weighted version of this measure corrects for possible biases in the unweighted } \\
\text { measure. The realized spread is measured using the standard tick test and using the hybrid } \\
\text { measure discussed in the text. Recall that the standard deviation of a sample mean is the } \\
\text { sample standard deviation divided by the square root of the number of observations. } \\
\text { Given the large numbers of observations available, the resulting sample mean standard } \\
\text { deviations are all tiny with respect to the differences in the sample means. }\end{array}$} \\
\hline
\end{tabular}




\begin{tabular}{|c|c|c|c|}
\hline \multicolumn{4}{|c|}{$\begin{array}{c}\text { Table } 3 \\
\text { Spread Regression Results }\end{array}$} \\
\hline Dependent variable: spread $s_{\mathrm{i}}$ & $\begin{array}{c}\text { Period I } \\
\text { open outcry }\end{array}$ & $\begin{array}{c}\text { Period II } \\
\text { screen trading }\end{array}$ & $\begin{array}{c}\text { Period III } \\
\text { screen trading }\end{array}$ \\
\hline Constant & $\begin{array}{c}1.68 \\
(1.96)\end{array}$ & $\begin{array}{l}-7.17 \\
(3.46)\end{array}$ & $\begin{array}{l}-2.00 \\
(3.46)\end{array}$ \\
\hline Lagged spread $s_{\mathrm{i}-1}$ & $\begin{array}{c}0.125 \\
(48.14)\end{array}$ & $\begin{array}{c}0.246 \\
(16.98)\end{array}$ & $\begin{array}{c}0.229 \\
(41.51)\end{array}$ \\
\hline Lagged spread $s_{\mathrm{i}-2}$ & $\begin{array}{c}0.055 \\
(24.49)\end{array}$ & $\begin{array}{c}0.069 \\
(14.58)\end{array}$ & $\begin{array}{c}0.088 \\
(53.01)\end{array}$ \\
\hline Lagged spread $s_{\mathrm{i}(-3,-25)}$ & $\begin{array}{c}0.161 \\
(30.95)\end{array}$ & $\begin{array}{c}0.109 \\
(12.97)\end{array}$ & $\begin{array}{c}0.197 \\
(64.60)\end{array}$ \\
\hline $\log$ volume $\ln V_{\mathrm{i}-1}$ & $\begin{array}{c}0.044 \\
(0.56)\end{array}$ & $\begin{array}{l}0.620 \\
(5.50)\end{array}$ & $\begin{array}{l}0.064 \\
(2.70)\end{array}$ \\
\hline Lagged $\log$ volume $\ln V_{\mathrm{i}-2}$ & $\begin{array}{c}-0.064 \\
(1.92)\end{array}$ & $\begin{array}{l}0.308 \\
(5.83)\end{array}$ & $\begin{array}{c}0.191 \\
(12.45)\end{array}$ \\
\hline Lagged $\log$ volume $\ln V_{\mathrm{i}(-3,-25)}$ & $\begin{array}{l}0.695 \\
(2.80)\end{array}$ & $\begin{array}{l}1.983 \\
(8.53)\end{array}$ & $\begin{array}{c}1.239 \\
(18.72)\end{array}$ \\
\hline \# combined trades $\operatorname{com}_{\mathrm{i}}$ & & $\begin{array}{c}1.343 \\
(10.95)\end{array}$ & $\begin{array}{c}0.935 \\
(24.07)\end{array}$ \\
\hline Volatility $\sigma_{i}$ & $\begin{array}{c}0.735 \\
(12.57)\end{array}$ & $\begin{array}{c}0.969 \\
(24.14)\end{array}$ & $\begin{array}{c}0.773 \\
(51.35)\end{array}$ \\
\hline volatility x volume $\sigma_{\mathrm{i}} \mathrm{x} \ln V_{\mathrm{i}(-3,-25)}$ & $\begin{array}{l}-0.568 \\
(3.41)\end{array}$ & $\begin{array}{l}-1.757 \\
(11.31)\end{array}$ & $\begin{array}{l}-1.365 \\
(21.16)\end{array}$ \\
\hline $\log$ inter-trade duration $\ln D_{\mathrm{i}-1}$ & $\begin{array}{l}0.237 \\
(2.99)\end{array}$ & $\begin{array}{l}-1.111 \\
(24.63)\end{array}$ & $\begin{array}{c}-0.560 \\
(52.58)\end{array}$ \\
\hline Lagged $\log$ inter-trade duration $\ln D_{\mathrm{i}-2}$ & 0.125 & -0.516 & -0.295 \\
\hline . & $\begin{array}{l}(2.85) \\
0.075\end{array}$ & $\begin{array}{c}(12.19) \\
1.462\end{array}$ & $\begin{array}{c}(28.52) \\
0.854\end{array}$ \\
\hline Lagged $\log$ inter-trade duration $\ln D_{\mathrm{i}(-3,-25)}$ & $(0.91)$ & $(14.02)$ & $(43.16)$ \\
\hline Quotes/trades qtratio $_{\mathrm{i}}$ & $\begin{array}{l}-1.42 \\
(1.51)\end{array}$ & $\begin{array}{l}-4.53 \\
(15.72)\end{array}$ & $\begin{array}{l}-2.87 \\
(45.40)\end{array}$ \\
\hline number of observations & 472,212 & 104,678 & $1,910,435$ \\
\hline number of observations used & 200,852 & 48,620 & 824,992 \\
\hline Heckman selection parameter $\lambda_{\mathrm{i}}$ & $\begin{array}{l}-0.292 \\
(-0.17)\end{array}$ & $\begin{array}{c}7.72 \\
(4.98)\end{array}$ & $\begin{array}{c}3.07 \\
(9.19)\end{array}$ \\
\hline mean of dependent variable & 17.42 & 17.59 & 13.71 \\
\hline s.d. of dependent variable & 8.55 & 14.14 & 9.26 \\
\hline $\mathrm{R}^{2}$ & 0.116 & 0.205 & 0.148 \\
\hline equation standard error & 8.04 & 12.17 & 8.55 \\
\hline
\end{tabular}




\begin{tabular}{|c|c|c|c|c|c|c|}
\hline \multicolumn{7}{|c|}{$\begin{array}{c}\text { Table } 4 \\
\text { Decomposition of Spread Changes (index points) }\end{array}$} \\
\hline & \multicolumn{2}{|c|}{$\begin{array}{c}\text { Total } \\
\text { Decomposition } \\
\Delta_{m}\left(\theta_{j} \bar{x}_{j}\right)\end{array}$} & \multicolumn{2}{|c|}{$\begin{array}{c}\text { Input } \\
\text { Component } \\
\theta_{j}^{1} \Delta_{m} \bar{x}_{j}\end{array}$} & \multicolumn{2}{|c|}{$\begin{array}{c}\text { Structure } \\
\text { Component } \\
\bar{x}_{j}^{m} \Delta \theta_{j}\end{array}$} \\
\hline & $\begin{array}{c}\text { Period } \\
\text { II }\end{array}$ & $\begin{array}{c}\text { Period } \\
\text { III }\end{array}$ & $\begin{array}{c}\text { Period } \\
\text { II }\end{array}$ & $\begin{array}{c}\text { Period } \\
\text { III }\end{array}$ & $\begin{array}{c}\text { Period } \\
\text { II }\end{array}$ & $\begin{array}{c}\text { Period } \\
\text { III }\end{array}$ \\
\hline Volume & 0.47 & 0.09 & -0.46 & -0.39 & 0.92 & 0.47 \\
\hline Volatility & 0.12 & -0.26 & 0.03 & -0.28 & 0.08 & 0.03 \\
\hline Liquidity (duration) & -0.01 & -0.04 & 0.10 & 0.04 & -0.11 & -0.08 \\
\hline Competitive pressure & -0.70 & -0.46 & -0.24 & -0.16 & -0.46 & -0.31 \\
\hline Split transactions & 0.27 & 0.21 & 0.04 & 0.02 & 0.23 & 0.19 \\
\hline Residual + approximation error & -0.24 & 0.05 & -0.16 & 0.03 & -0.08 & 0.03 \\
\hline Total & -0.10 & -0.41 & -0.69 & -0.74 & 0.59 & 0.34 \\
\hline \multicolumn{7}{|c|}{$\begin{array}{l}\text { The initial column of the table gives the overall change in the spread (index points) attributable } \\
\text { to each variable based on the tick regression results reported in Table 5. The final four columns } \\
\text { of the table gives the results of the two alternative Blinder-Oaxaca decompositions of average } \\
\text { spread changes between Periods I respectively Periods II and III. This decomposition breaks } \\
\text { down the overall change into a component due to the change in the driving variable and a } \\
\text { component relating to a change in the structure of spread determination - see equation (2). } \\
\text { Column totals may differ slightly from the sum of their elements through rounding. }\end{array}$} \\
\hline
\end{tabular}




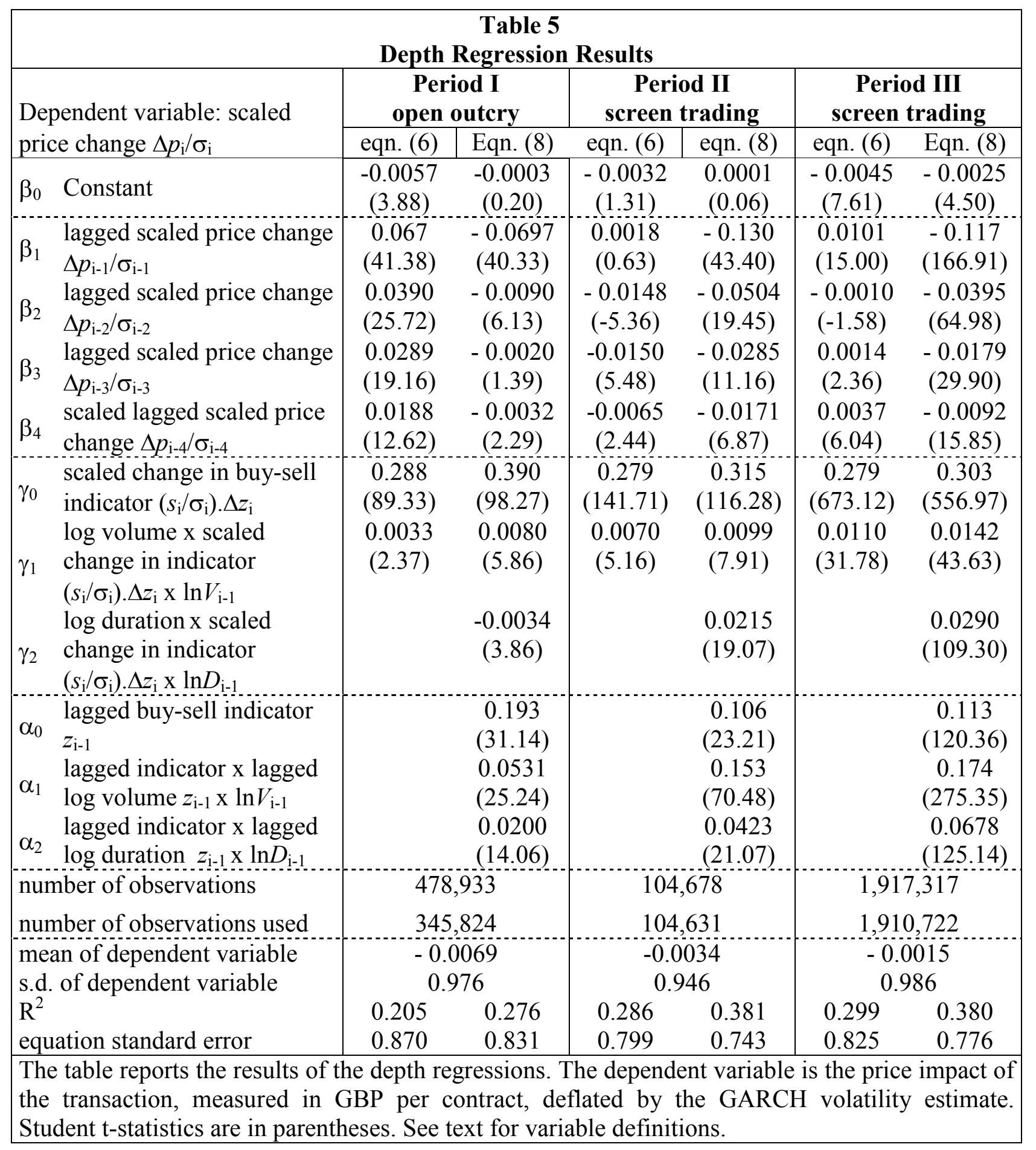




\begin{tabular}{|c|c|c|}
\hline \multicolumn{3}{|c|}{$\begin{array}{c}\text { Table } 6 \\
\text { Price Impact Regression } \\
\end{array}$} \\
\hline \multicolumn{3}{|c|}{$\begin{array}{l}\text { Dependent variable: price impact }=\text { abs (average price of all components of the } \\
\text { combined trade }- \text { price of first component) }\end{array}$} \\
\hline & Period II & Period III \\
\hline constant & $\begin{array}{c}-6.44 \\
(16.18)\end{array}$ & $\begin{array}{c}-5.33 \\
(79.82)\end{array}$ \\
\hline volume of combined trade $V_{\mathrm{i}}$ & $\begin{array}{l}0.0409 \\
(4.06)\end{array}$ & $\begin{array}{l}0.0905 \\
(44.98)\end{array}$ \\
\hline squared volume of combined trade $V_{\mathrm{i}}^{2}$ & $\begin{array}{c}-0.00013 \\
(0.90)\end{array}$ & $\begin{array}{c}-0.00065 \\
(20.23)\end{array}$ \\
\hline components & $\begin{array}{c}4.935 \\
(61.23)\end{array}$ & $\begin{array}{c}3.879 \\
(263.94)\end{array}$ \\
\hline lagged spread $s_{\mathrm{i}-1}$ & $\begin{array}{l}0.0098 \\
(2.05)\end{array}$ & $\begin{array}{l}0.0081 \\
(6.42)\end{array}$ \\
\hline lagged spread $s_{i-2}$ & $\begin{array}{l}0.0132 \\
(2.79)\end{array}$ & $\begin{array}{l}0.0140 \\
(11.37)\end{array}$ \\
\hline lagged spread $s_{\mathrm{i}(--3,-25)}$ & $\begin{array}{l}0.0895 \\
(11.03)\end{array}$ & $\begin{array}{l}0.0556 \\
(24.99)\end{array}$ \\
\hline volatility $\sigma_{i}$ & $\begin{array}{c}0.177 \\
(13.46)\end{array}$ & $\begin{array}{l}0.125 \\
(32.23)\end{array}$ \\
\hline lagged $\log$ duration $\ln D_{\mathrm{i}-1}$ & $\begin{array}{l}-0.220 \\
(4.71)\end{array}$ & $\begin{array}{l}-0.119 \\
(13.90)\end{array}$ \\
\hline lagged $\log$ duration $\ln D_{\mathrm{i}-2}$ & $\begin{array}{c}-0.048 \\
(1.03)\end{array}$ & $\begin{array}{r}-0.047 \\
(5.49)\end{array}$ \\
\hline lagged $\log$ duration $\ln D_{\mathrm{i}(-3,-25)}$ & $\begin{array}{l}0.608 \\
(5.80)\end{array}$ & $\begin{array}{c}0.277 \\
(16.63)\end{array}$ \\
\hline quotes/trades qtratio & $\begin{array}{r}-2.951 \\
(9.34)\end{array}$ & $\begin{array}{l}-1.087 \\
(20.89)\end{array}$ \\
\hline number of observations & 11025 & 143422 \\
\hline mean of dependent variable & 7.50 & 6.08 \\
\hline s.d. of dependent variable & 8.08 & 5.73 \\
\hline $\mathrm{R}^{2}$ & 0.349 & 0.448 \\
\hline equation standard error & 6.32 & 4.25 \\
\hline $\begin{array}{l}\text { The table reports the estimated regress } \\
\text { in GBP per contract) identified as hav } \\
\text { by the LIFFE CONNECT trading alg } \\
\text { the number of estimated trades into wh }\end{array}$ & $\begin{array}{l}\text { he price im } \\
\text { n split agai } \\
\text { The variab } \\
\text { combined tr }\end{array}$ & $\begin{array}{l}\text { ades (measu } \\
\text { than one qu } \\
\text { nents measu } \\
\text { een split. }\end{array}$ \\
\hline
\end{tabular}


Elenco dei papers del Dipartimento di Economia

2000.1 A two-sector model of the effects of wage compression on unemployment and industry distribution of employment, by Luigi Bonatti

2000.2 From Kuwait to Kosovo: What have we learned? Reflections on globalization and peace, by Roberto Tamborini

2000.3 Metodo e valutazione in economia. Dall'apriorismo a Friedman, by Matteo Motterlini

2000.4 Under tertiarisation and unemployment. by Maurizio Pugno

2001.1 Growth and Monetary Rules in a Model with Competitive Labor Markets, by Luigi Bonatti.

2001.2 Profit Versus Non-Profit Firms in the Service Sector: an Analysis of the Employment and Welfare Implications, by Luigi Bonatti, Carlo Borzaga and Luigi Mittone.

2001.3 Statistical Economic Approach to Mixed Stock-Flows Dynamic Models in Macroeconomics, by Bernardo Maggi and Giuseppe Espa.

2001.4 The monetary transmission mechanism in Italy: The credit channel and a missing ring, by Riccardo Fiorentini and Roberto Tamborini.

2001.5 Vat evasion: an experimental approach, by Luigi Mittone

2001.6 Decomposability and Modularity of Economic Interactions, by Luigi Marengo, Corrado Pasquali and Marco Valente.

2001.7 Unbalanced Growth and Women's Homework, by Maurizio Pugno

2002.1 The Underground Economy and the Underdevelopment Trap, by Maria Rosaria Carillo and Maurizio Pugno.

2002.2 Interregional Income Redistribution and Convergence in a Model with Perfect Capital Mobility and Unionized Labor Markets, by Luigi Bonatti.

2002.3 Firms' bankruptcy and turnover in a macroeconomy, by Marco Bee, Giuseppe Espa and Roberto Tamborini.

2002.4 One "monetary giant" with many "fiscal dwarfs": the efficiency of macroeconomic stabilization policies in the European Monetary Union, by Roberto Tamborini.

2002.5 The Boom that never was? Latin American Loans in London 1822-1825, by Giorgio Fodor. 
2002.6 L'economia senza banditore di Axel Leijonhufoud: le 'forze oscure del tempo e dell'ignoranza' e la complessità del coordinamento, by Elisabetta De Antoni.

2002.7 Why is Trade between the European Union and the Transition Economies Vertical?, by Hubert Gabrisch and Maria Luigia Segnana.

2003.1 The service paradox and endogenous economic gorwth, by Maurizio Pugno.

2003.2 Mappe di probabilità di sito archeologico: un passo avanti, di Giuseppe Espa, Roberto Benedetti, Anna De Meo e Salvatore Espa.

(Probability maps of archaeological site location: one step beyond, by Giuseppe Espa, Roberto Benedetti, Anna De Meo and Salvatore Espa).

2003.3 The Long Swings in Economic Understianding, by Axel Leijonhufvud.

2003.4 Dinamica strutturale e occupazione nei servizi, di Giulia Felice.

2003.5 The Desirable Organizational Structure for Evolutionary Firms in Static Landscapes, by Nicolás Garrido.

2003.6 The Financial Markets and Wealth Effects on Consumption An Experimental Analysis, by Matteo Ploner.

2003.7 Essays on Computable Economics, Methodology and the Philosophy of Science, by Kumaraswamy Velupillai.

2003.8 Economics and the Complexity Vision: Chimerical Partners or Elysian Adventurers?, by Kumaraswamy Velupillai.

2003.9 Contratto d'area cooperativo contro il rischio sistemico di produzione in agricoltura, di Luciano Pilati e Vasco Boatto.

2003.10 Il contratto della docenza universitaria. Un problema multi-tasking, di Roberto Tamborini.

2004.1 Razionalità e motivazioni affettive: nuove idee dalla neurobiologia e psichiatria per la teoria economica? di Maurizio Pugno.

(Rationality and affective motivations: new ideas from neurobiology and psychiatry for economic theory? by Maurizio Pugno.

2004.2 The economic consequences of Mr. G. W. Bush's foreign policy. Can th US afford it? by Roberto Tamborini

2004.3 Fighting Poverty as a Worldwide Goal by Rubens Ricupero

2004.4 Commodity Prices and Debt Sustainability by Christopher L. Gilbert and Alexandra Tabova

2004.5 A Primer on the Tools and Concepts of Computable Economics by K. Vela Velupillai 
2004.6 The Unreasonable Ineffectiveness of Mathematics in Economics by Vela K. Velupillai

2004.7 Hicksian Visions and Vignettes on (Non Linear) Trade Cycle Theories by Vela K. Velupillai.

2004.8 Trade, inequality and pro-poor growth: Two perspectives, one message? by Gabriella Berloffa and Maria Luigia Segnana.

2004.9 Worker involvement in entrepreneurial nonprofit organizations. Toward a new assessment of workers? Perceived satisfaction and fairness by Carlo Borzaga and Ermanno Tortia.

2004.10 A Social Contract Account for CSR as Extended Model of Corporate Governance (Part I): Rational Bargaining and Justification by Lorenzo Sacconi

2004.11 A Social Contract Account for CSR as Extended Model of Corporate Governance (Part II): Compliance, Reputation and Reciprocity by Lorenzo Sacconi

2004.12 A Fuzzy Logic and Default Reasoning Model of Social Norm and Equilibrium Selection in Games under Unforeseen Contingencies by Lorenzo Sacconi and Stefano Moretti

2004.13 The Constitution of the Not-For-Profit Organisation: Reciprocal Conformity to Morality by Gianluca Grimalda and Lorenzo Sacconi

2005.1 The happiness paradox: a formal explanation from psycho-economics by Maurizio Pugno

2005.2 Euro Bonds: in Search of Financial Spillovers by Stefano Schiavo

2005.3 On Maximum Likelihood Estimation of Operational Loss Distributions by Marco Bee

2005.4 An enclave-led model growth: the structural problem of informality persistence in Latin America by Mario Cimoli, Annalisa Primi and Maurizio Pugno

2005.5 A tree-based approach to forming strata in multipurpose business surveys, by Roberto Benedetti, Giuseppe Espa and Giovanni Lafratta.

2005.6 Price Discovery in the Aluminium Market, by Isabel Figuerola-Ferretti and Christopher L. Gilbert.

2005.7 How is Futures Trading Affected by the Move to a Computerized Trading System? Lessons from the LIFFE FTSE 100 Contract, by Christopher L. Gilbert and Herbert A. Rijken 
PUBBLICAZIONE REGISTRATA PRESSO IL TRIBUNALE DI TRENTO 